DOI: $10.31249 / \mathrm{rsm} / 2020.03 .03$

\title{
B.A. Аватков
}

\section{ИАЕЙНЫЙ ФАКТОР И ТЮРКСКИЙ ЭАЕМЕНТ В ПОАИТИКЕ РОССИИ СКВОЗЬ ПРИЗМУ ТРАНСФОРМАЦИИ МИРОВОГО ПОРЯАКА}

Аннотация. Статья посвящена идейному и тюркскому факторам в политике современной России. Автор исходит из того, что после распада Советского Союза Россия отрицала необходимость идейного фактора, поэтому не имела каких-либо устойчивых идеологем, которые являются основой движения и развития государства. По прошествии времени мировой порядок и приоритеть Российской Федерации изменились, а появился отчетливый запрос на поиск новых идей. Проанализировав ряд работ российских исследователей, автор приходит к выводу о том, что современному миру свойственно соревнование политических моделей и идеологем, вследствие чего особую важность приобретает формирование нарративов, которые должны соответствовать национальным интересам.

Россия нуждается в формировании идеологий как на внешнеполитическом, так и на внутриполитическом направлениях. Автор подчеркивает, что в наши дни государство находится в поиске правильных ориентиров. Во внешней политике государства существует концепция "русского мира», практическая реализация которой, однако, далека от идеальной. Предполагается, что мировыми процессами будут управлять те государства, которые будут уделять внимание новым объединениям. Одним из факторов сближения субъектов, в свою очередь, может стать идеал справедливости, свойственный как для западного общества, так и для восточного.

Особую важность для России также приобретает тюркский фактор, оказывающий серьезное влияние на формирование идеологем. Главная задача России на этом направлении заключается в защите тюркоязычных субъектов государства от внешнего влияния, а также в поиске компромиссов с создающими угрозу внешними акторами, одним из которых является Турция.

Ключевые слова: Россия; мировой порядок; международные отночения; полииентричность; идеологемы; идейный фактор; тюркский фактор.

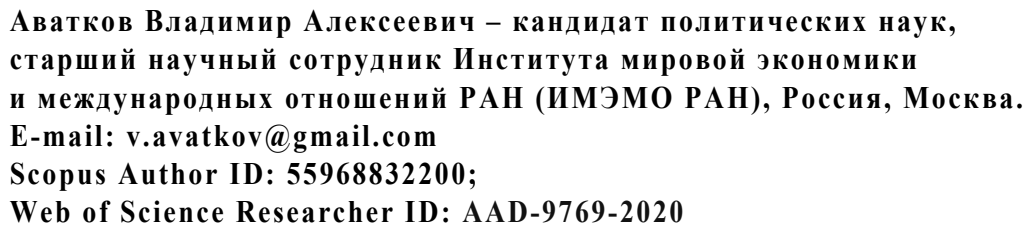




\section{Avatkov V.A. The Ideological Factor and the Turkic Element in Russia's Policy through the Prism of Transformation of the World Order}

Abstract. Examining ideological and Turkic factors in Russia's contemporary policy, the author proceeds from the fact that after the disintegration of the Soviet Union, Russia abandoned the very idea of state ideology. As a result, it had no solid ideologemes that could form the basis for the proper development of the state. However, as time passed, the world order as well as the priorities of the Russian Federation were changing and there appeared a visible demand for new ideas. For this reason, the society now is in acute need for new narratives that will correspond to the vital national interests both internationally and domestically.

Today, the state is evidently in search for new ways forward. In foreign policy, there is a concept of the "Russian world», the practical implementation of which is, however, still far from ideal. It is anticipated that the global processes would be directed by the states that pay close attention to new international associations. The ideal of justice that is typical both for the West and East could be one of those factors that might greatly contribute to the reconciliation of the world's societies.

What assumes particular importance for Russia is the Turkic factor. Russia's most important task is to safeguard the Turkic-speaking regions of the country from external influence, while finding a compromise with external actors that pose a threat to such regions. Central in this regard are our relations with Turkey.

Keywords: Russia; the world order; international relations; polycentrism; ideologies; the ideological factor; Turkic factor.

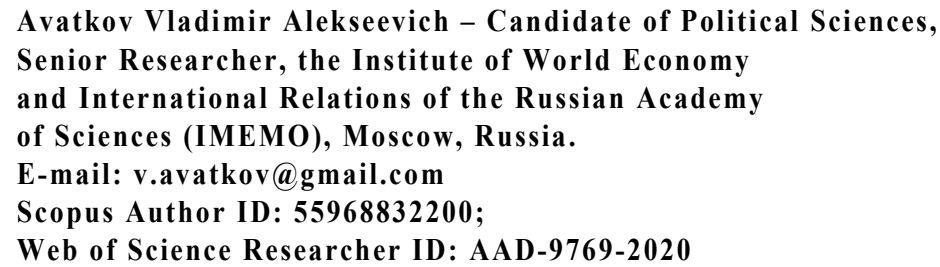

После развала СССР Россия пережила логичный с точки зрения исторического процесса этап отрицания идейного фактора во всех сферах жизни, этап концентрации на интересах, а не ценностях в политической жизни. Смена вех, диктуемая развитием мира и государства, ставит перед элитой и населением страны естественные вопросы о будущем, а значит требует и выработки концептуальных основ - набора устойчивых идеологем. Без такого философского обоснования будущего страны и мира государство обречено на следование чужим логикам или (само)ликвидацию. Осознание этого факта не до конца пришло в нужные точки, структуры и элементы политического истеблишмента, однако дух перемен уже отчетливо ощущается. 


\section{Мировые тенденции и мировой контекст}

Несмотря на дискуссию о «конце истории» и расхожие формулировки о наступлении эры национальных интересов, эры отрицания идейного базиса развития общества, мировая политическая среда после этапа постсоветского сосредоточения стала искать - что естественно - новые ориентиры. Сама среда (бесспорно, не без участия акторов) сформировала запрос на идеи, пусть и не глобального характера, но на микроуровне.

Такого рода поиск и сосредоточение привели к возвращению на мировую арену религиозного сознания, консервативных тенденций и национализма в различных его проявлениях. Более того, в отдельных случаях наблюдается превращение указанных факторов в крайне взрывоопасную смесь с точки зрения системы международных отношений. XXI век переживает «кризис рациональной всемирности», который, по многим имеющимся тенденциям, происходит в виде «возвращения в эпоху религиозных войн» [Косолапов 2006].

В связи с нестандартным межсистемным переходом, который, судя по всему, не завершился до сих пор, возникли дискуссии относительно сложившегося и будущего миропорядка.

Существует научная позиция, содержание которой сводится к тому, что система международных отношений продолжает по большей части сохранять признаки Ялтинско-Потсдамского периода, что обосновывается, прежде всего, сохранением ключевых институтов, включая ООН. Оппоненты же указывают на то, что развал СССР, т.е. геополитическая катастрофа, привел к краху одного из ключевых акторов, а значит создал предпосылки для перехода к новой системе. Исходя из этой логики, возникают две позиции - мир находится в стадии перехода или уже в новом порядке.

Наиболее верной в этом контексте представляется позиция, подразумевающая, что время ускорилось, мир после развала СССР пережил стадии однополярности, плюралистической однополярности [Богатуров, Косолапов, Хрусталев 2002, с. 284], а сейчас переходит сквозь «постзападную эру» [Никитина 2017] к полицентричности или бесполярности. Как отмечает академик А.А. Дынкин, «мировой порядок, который существовал последние 25 лет, сломлен», а «политическое содержание текущей трансформации мирового порядка заключается в столкновении претензий на американскую исключительность с реалиями полицентричного мира» [Дынкин 2015, с. 66].

Ряд исследователей отмечает, что из имеющихся концепций «самой перспективной ... представляется та, что основана на идее коллективного управления, осуществляемого группой ведущих демократических государств» [Иноземцев, Караганов 2005, с. 22]. 
В работах современных российских исследователей получили новое звучание мысли об идейном столкновении в мире [Караганов 2016]. Проводятся круглые столы по теме, обсуждаются вопросы кризиса и эволюции политических идеологий [Каменская, Соловьев, Смирнов 2015, с. 101].

Складывается ощущение, что мир вступает в новое идеологическое соревнование, в котором уже не будет тотальных идеологий и войны двух миров, но однозначно формируется соревнование политических моделей и идеологем, благодаря чему человечество сможет двигаться вперед. Для мира определяющим было и остается то, что происходит в головах людей, ответственных за принятие решений, мозговая деятельность и формирование идей важнее (или, по крайней мере, не менее важны) того, что содержится «в кошельках» [Войтоловский 2017, с. 159].

Член-корреспондент РАН Ал.А. Громыко отмечает, что история международных отношений может двигаться «рывками», когда более длительные периоды стабилизации и сменяются более короткими всплесками насилия. По его мнению, базисом формаций в этом контексте является экономика, но также и «цивилизационно-культурный, и религиозный, и ценностный факторы». В связи с этим необходимо формировать соответствующие нарративы, отвечающие национальным интересам. По мнению Ал.А. Громыко, у России есть положительный опыт формирования нарративов - «Русский мир», собственное видение глобализации, идеи суверенной внешней политики, позиционирование себя как «стратегически мыслящей державы» [Громыко 2016, c. 8].

Как отмечает член-корреспондент РАН Ф.Г. Войтоловский, «мир стоит на пороге появления новых идеологий», «отсутствие систематизированной идеологии представляет собой такую же опасность, как и сверхидеологизация политики». Для современной России эта проблема представляется особенно актуальной, с учетом того что «государство, элита которого не видит долгосрочных целей своей деятельности, не озабочено стратегическим целеполаганием, рискует оказаться жертвой текущих столкновений внешних и внутренних политико-экономических интересов или стать орудием достижения чуждых ему целей» [Войтоловский 2007, с. 55]. Именно поэтому идеологический фактор становится одним из определяющих - в том числе и для России, которая исторически предлагала миру альтернативу развития, но способна и может это сделать и сегодня.

\section{Россия в мире идей}

Бурная дискуссия о будущности идеологии, развернувшаяся в рамках эпохи «нового мышления» Горбачёва, прекратилась достаточно резко после таких событий, как развал СССР, обнищание интеллигенции, расстрел 
парламента в 1993 г. и чеченские войны. Потребовались годы созидательного труда, в первую очередь в сфере выстраивания заново государственных институтов, чтобы вновь появился запрос на идеологию внешне- и внутриполитического курса.

Как отмечал С.А. Караганов, «главная проблема заключается в том, что Россия легла в дрейф. Мы не знаем, куда двигаться» [Караганов 2013, с. 12]. Проблемой отсутствия четких ориентиров во внешней политике России озабочены многие исследователи. Так, Э.Г. Соловьев подчеркнул, что «позитивного консенсуса, четко выраженных собственных преференций, программы действий... в отечественной политике не выработано» [Соловьев 2008, с. 86]. Дефицит идей оказывается в этом контексте тесно связан с дефицитом привлекательности России [Соловьев, Смирнов 2008]. При этом очевидно, что Россия вследствие многих событий и трансформации мировой политической среды находится на этапе переформатирования своей внешней [Барановский 2016 , с. 8] и внутренней политики, в поисках новых - в том числе идейных ориентиров.

Все большее распространение при анализе роли ценностей в политике России получает связь между ними и исторической памятью [Пахалюк 2018, c. 135]. При этом обращение к прошлому может сформировать основу морального обоснования места, миссии и будущего России как в контексте внутренних ориентиров, так и в выстраивании внешнеполитического целеполагания.

Во внешней политике, бесспорно, войдет в историю концепт «русский мир», который можно трактовать в узком смысле слова - как мир проживающих во многих странах русских, так и в широком смысле - как все русскоязычное пространство. Иными словами, вторая трактовка выходит далеко за рамки ареала проживания русских на постсоветском пространстве и возвращает термину «русский» его исконную полиэтничность, подразумевающую, в первую очередь, опору на язык и самовосприятие, а отнюдь не на национальный признак.

Проблема «русского мира» кроется не в слабости самой идеи, а в недостаточности ее развития. Любой идейный конструкт требует выработки стратегии и тактики наступления, сценариев ответа при наличии вызовов в отношении него. Без всего вышеперечисленного любая идеология обречена на неудачу и естественную гибель.

Украинский кейс, который продемонстрировал крах имевшегося ранее миропорядка, оказался - по крайней мере в настоящий момент - угрозой, а затем и непреодолимым препятствием для «русского мира». Успешность «русской весны» в Крыму сменилась стагнацией на Донбассе и отрывом Киева, без которого «русский мир» неполон. Более того, сама привлекательность термина оказалась под угрозой, прочно (благодаря соответствующей анти- 
российской пропаганде) начала ассоциироваться у многих людей с агрессией, а не с миром и справедливостью.

Столкновение с испытанием продемонстрировали необходимость перестройки концепции «русский мир», создания должной стратегии воздействия и тактики работы. Жизнеспособность идеи не вызывает сомнения, однако казус исполнения налицо.

Для реализации внешнеполитической идеологии требуется слаженная работа всех органов власти - от МИДа до Россотрудничества и даже частных некоммерческих организаций. А есть ли она, эта внешнеполитическая идеология, у современной России?

Совокупность даже самых правильных действий не может заменить идейный концепт. Цели движения должны быть обозначены на доктринальном уровне и отражаться в концепции внешней политики и иных государственных документах.

Сирийский кейс продемонстрировал успехи внешней политики и военной силы России, но он же и обнажил вопрос о будущности мира, региона и Российского государства. После успехов на военном и дипломатическом уровнях от Москвы ждут свойственных ей на протяжении истории идей развития, особенно ждут на постсоветском пространстве.

«Суверенная демократия» - при всем том, что это «масло масляное»работающий концепт, потому что большинство государств в той или иной степени устали от протектората США, которые после развала СССР определили себя победителями и начали строить однополярный мир - мир гегемонии. Волнение элементов мировой системы усиливается с каждым действием «слона в посудной лавке» - будь то ливийский кейс, или египетский, или иракский.

Но действительно ли это тот концепт, который подходит современной России? Ограничиваться опорой на себя и собственные силы во всем недостаточно, идеи чучхе работают только в закрытом обществе, которое возродить можно - но нужно ли? - только диктаторской рукой. При этом «унификация, эрозия идентичности, ослабление национально-государственных возможностей регулирования социума... могут вызывать в качестве защитной реакции приступы самоизоляции, автаркии, протекционизма» [Барановский 2010, с. 8 ], это во многом объясняет причинно-следственные связи описанного выше.

Бесспорно, «суверенная демократия» вписывается и в идею укрепления полицентричного мира. Но и тут возникает целый ряд закономерных вопросов. Полицентричный мир более демократичен, чем однополярный и биполярный. Он был свойствен системе международных отношений на протяжении истории - исключением стали лишь 50 лет биполярного противостояния и 15 лет гегемонии одного игрока. Но мир полицентричный - это не только 
демократия, но и расширение хаоса, а значит - большая опасность, особенно с учетом недостаточности ответственности у региональных акторов. Иными словами, такого рода мировой порядок может стать предтечей новых войн.

Полицентричность в истории была таким же естественным явлением, как и стремление государств к объединению в два блока для большего порядка и сохранения мира. Достаточно в качестве примеров вспомнить Антанту и Четверной союз, антинаполеоновские коалиции, многие войны, в которых участвовала Россия. Будущее за теми, кто возглавит процесс создания новых объединений, а значит - вполне логичным оказывается попытка в том числе Москвы делать акцент на БРИКС и ШОС.

Учитывая «разворот России на Восток» и рост значения этого региона в мире, логичным будет искать единые с ним идейные концепты - при этом, бесспорно, не допуская полной изоляции от Запада: восточные государства могут воспринять это как возможность использовать Москву в своих целях.

Восток исторически имел свои особенности, отличающие его от Запада. Это и цикличность времени, и концентрация на лидерстве, а не на институтах, особое отношение к собственности и сакральности, общинность. Но главный концепт Востока - справедливость. За нее ведется борьба, из-за нее делаются революции, она определяет политическое и экономическое сознание большей части групп населения.

Сложившаяся система международных отношений «значительно более однородна, чем все прежние в смысле составляющих ее основание ценностей», но она «содержит большой элемент несправедливости, а поэтому и не может быть вполне устойчивой» [Кременюк 2004, с. 39].

Одним из стержней, объединяющих народы на протяжении истории, был и остается стержень справедливости. Такого рода стержней, скреп должно быть выявлено и постулировано как можно больше: именно они должны составить основу новой национальной идеи идеального будущего. Подобного рода модель идеального будущего, основанного, в первую очередь, на интересах российской (русской) нации, постепенно может и должна стать привлекательной не только для внутреннего потребления, но и для мирового сообщества. Для этого необходимо на экспертном уровне выявить схожие черты, модели идеального будущего и восприятия прошлого у новой российской (русской) нации и других наций мира. Например, идеал справедливости может стать базисом взаимодействия со многими субъектами мировой политики, потому что этот идеал играет большую роль во многих и западных, и восточных обществах. Особенно остро он чувствуется у тех народов, которые находятся на пересечении Запада и Востока. Примером может послужить Турция, у которой этот идеал непостулированно заложен в идеологию правящей элиты. Это проявляется даже в названии правящей партии - Партии справедливости и развития [Аватков 2016, с. 688].

\section{4}


Справедливость может и должна стать объединяющим фактором, с которым можно проводить собственную политику. Слово не может быть выброшено из контекста и требует проработки соответствующей стратегии, а затем и тактики. Учет всех особенностей развития восточных государств и интересов, традиций и ценностей России может сформировать новую внешнеполитическую идеологию государства - идеологию, привлекательную для всех.

Кроме того, справедливость может стать ключевой частью не только внешнеполитической идеологии, но и концепции внутреннего развития. Ведь основные претензии населения к власти касаются именно справедливости справедливости распределения доходов, справедливости назначения на должности, справедливости принятия тех или иных решений.

Парадоксальным образом по большинству классических параметров Востока Россия - страна, скорее, восточная. А значит, целый ряд закономерных процессов, вопросов и идей Востока свойственны и Российскому государству. Использование указанных факторов может сыграть на пользу укрепления России.

\section{Тюркский фактор в политике России}

Особое влияние на формирование идеологем во внешней политике России в последнее время оказывает тюркский фактор, состоящий из трех элементов: внутренней составляющей, тюркоязычных регионов, входящих в состав государства, пространства СНГ в лице представляющих Содружество тюркских государств, а также политики внешних акторов, заключающейся в распространении своего влияния и создании так называемого «тюркского мира».

Принципиально важным элементом являются именно тюркоязычные субъекты, поскольку они представляют собой основу существования самой России, в том числе и как многонационального государства. Важность этой внутренней составляющей состоит также в том, что она, как правило, определяет идеологию государства в отношении тюркских и тюркоязычных народов. Формируется такая идеология постепенно - иногда, как в случае с Россией, которая после распада Советского Союза в силу сложившихся обстоятельств уделяла недостаточно внимания тюркоязычному населению страны, этот процесс занимает годы и даже десятилетия.

В настоящее время Россия нацелена на гармонизацию межнациональных отношений внутри страны и укрепление сотрудничества с тюркоязычными народами СНГ, при укреплении контактов с Турцией, но при сохранении дистанции.

В этом контексте особую значимость приобретает сохранение самобытности народов. Так, например, тюркоязычное население России осознает, что, 
несмотря на некоторые этнические особенности, многовековая история и культура тесно связывают эти народы с Российской Федерацией. Говоря о тюркских государствах постсоветского пространства, стоит отметить, что в отношении них произошла относительная интеграция, усиливается внешнее влияние на них, однако разрозненные контакты России с ними пока не приобрели структурную и долгосрочную основу, которая гарантировала бы в перспективе реализацию интересов и России, и этих государств.

Вместе с тем главная задача России состоит в том, чтобы оборонять внутренний фактор от внешнего влияния и исходящих «извне» угроз. Одну из такого рода угроз представляет собой политика отдельных государств, направленная на разрушение самобытности и подмену российских идеологий противоположными по смыслу идеями.

Наиболее активно такую политику проводит Турецкая Республика, которая с начала 2000-х годов проявляет особый интерес к тюркоязычным регионам России и тюркским государствам постсоветского пространства. Турция пытается выстроить линии сотрудничества практически с каждым из таких государств [Дружиловский, Аватков 2013, с. 86], стараясь приблизиться к ним за счет осуществления политики пантюркизма. При этом Турция больше не рассматривает эти государства в качестве своих партнеров. Они скорее представляют собой вспомогательный инструмент, используемый для достижения целей, поставленных в рамках провозглашенной Турцией политики неоосманизма, предусматривающей возвращение Турецкой Республике утраченного влияния и являющейся причиной ее чрезмерных амбиций.

С момента распада СССР Турция, в основном посредством «мягкой силы», оказывала существенное влияние как на отдельные страны СНГ, так и на российские регионы, что в значительной степени осложняло процесс российскотурецкого взаимодействия.

На территории некоторых тюркоязычных республик Российской Федерации функционировали «турецкие лицеи», деятельность которых впоследствии была признана экстремистской и приостановлена на основании решения Верховного суда, а в тюркских государствах Центральной Азии особенно распространились культурные и другие центры, управляемые из Турции (ТИКА, ТЮРКСОЙ).

И если несколько лет назад в Турции были популярны мысли о провозглашении Турана - мифического протогосударства тюркских народов, то в последние годы руководство страны пропагандирует идею создания «тюркского мира», которая заключается в объединении всех тюркских народов под эгидой Турецкой Республики и на основе турецких логик. Власти государства красноречиво говорят об их единстве, которое, однако, ничем не подтверждается. Турция активно дает понять, что готова выступить в роли предводителя мира тюркских государств, однако, чтобы не вызывать лишнего возмущения, 46 
осуществляет свою цель достаточно аккуратно, переходя от линии конфронтации к линии сотрудничества. Кроме того, Турция намеренно не делает различий между понятиями «турецкий», «тюркский» и «тюркоязычный», полагая, что отдельно взятые схожие культурные и другие аспекты дают право делать такого рода громкие заявления о необходимости объединения народов на основе турецких логик.

Россия, внешняя политика которой все чаще смещается в сторону тюркского фактора, напротив, старается убедить Турцию в обратном. При этом для России остается принципиально важным сохранить не только связи с тюркскими и тюркоязычными регионами, но и установленные за годы многолетнего сотрудничества контакты с Турецкой Республикой. Тюркский фактор сегодня является одним из важнейших пунктов политики России на внешнеполитическом направлении, и одной из главных задач остается защита тюркоязычных субъектов от внешнего влияния, а также поиск баланса с внешними акторами, и в первую очередь - с Турцией.

В идейном факторе внешней политики России ключевым этнополитическим фактором является «тюркский вопрос». Он тесно связан с внутренним пространством, а также с ключевыми с точки зрения российской внешней политики странами - странами СНГ. Можно сказать, что тюркский фактор будет являться лакмусовой бумажкой успехов и поражений Москвы в деле выстраивания внешнеполитической идеологии (впрочем, на самом деле и идеологии внутренней). Четкое разделение тюркского «поля» на тюркоязычные российские народы, тюркские народы СНГ и Турцию, уважение к традициям и поощрение различий в противовес турецкому господству станет хорошим началом большого дела по формированию нового ценностного поля российской внешней политики - «Политики справедливости».

\section{Библиография}

Аватков В.А. О нации, идентичности и логиках современной России: основные сложности и решения // Национальная безопасность. 2016. № 6 (47). С. 685-689.

Барановский В.Г. Трансформация мировой системы в 2000-х годах // Международные процессы. 2010. Т. 8. № 1 (22). С. 4-13.

Барановский В.Г. Новая внешняя политика России: влияние на международную систему // Мировая экономика и международные отношения. 2016. Т. 60. № 7. С. 5-15.

Богатуров А.Д., Косолапов Н.А., Хрусталев М.А. Очерки теории и методологии политического анализа международных отношений. М.: НОФМО, 2002. 390 с.

Войтоловский Ф.Г. Идеологическая рефлексия мировой политики // Международные процессы. 2007. Т. 5. № 3 (15). С. 44-56.

Войтоловский Ф.Г. Определение стратегических целей - это сфера идеологии... // Международные процессы. 2017. Т. 15. № 1 (48). С. 157-168.

Громыко Ал.А. Постоянство и изменчивость в истории международных отношений // Современная Европа. 2016. № 1 (67). С. 5-8. 
Дружиловский С.Б., Аватков В.А. Внешнеполитические идеологемы Турции (20022012 гг.) // Обозреватель. 2013. № 6 (281). С. 73-88.

Дынкин А.А. Кризис миропорядка: поиски выхода // Научные труды Вольного экономического общества России. 2015. Т. 196. С. 63-73.

Иноземцев В., Караганов С. О мировом порядке XXI века // Россия в глобальной политике. 2005. Т. 3. № 1. С. $8-26$.

Каменская Г.В., Соловьев Э.Г., Смирнов А.Н. Политические идеологии в современном мире: кризис или очередной этап эволюции? // Власть. 2015. Т. 23. № 12. С. 101-108.

Караганов С. Россия в мире перемен // Россия и мусульманский мир. 2013. № 10 (256). C. 5-21.

Караганов С. Новая идеологическая борьба? // Известия. 2016. 21 апреля. URL: https:// iz.ru/news/610812 (дата обращения: 11.05.2019).

Косолапов Н.А. Кризис рациональной всемирности // Международные процессы. 2006. T. 4. № 10. С. 55-67.

Кременюк В.А. Управление и управляемость в мировой политике // Международные процессы. 2004. Т. 2. № 3 (6). С. 29-39.

Никитина О. Лавров: Мир становится постзападным // Взгляд. 2017. 9 марта. URL: https:// vz.ru/news/2017/3/9/861152.html (дата обращения: 11.05.2019).

Пахалюк К.А. «Мягкая сила» и политика памяти в контексте внешней политики современной России: точки пересечения // Дневник АШПИ. 2018. № 34. С. 134-141.

Соловьев Э.Г., Смирнов А.Н. Международный имидж современной России: дефицит привлекательности или дефицит идей? // Полис. Политические исследования. 2008. № 5. С. 19-33.

Соловьев Э.Г. Рукотворный контекст этнополитики // Международные процессы. 2008. T. 6. № 1 (16). С. 86-92.

\section{References}

Avatkov V.A. O nacii, identichnosti i logikax sovremennoj Rossii: osnovny`e slozhnosti i resheniya. Nacional naya bezopasnost [About the nation, identity and logics of modern Russia: the main difficulties and decisions. National Security]. 2016. N 6 (47). P. 685-689. (In Russ.)

Baranovskij V.G. Transformaciya mirovoj sistemy v 2000-x godax. Mezhdunarodny’e processy [Transformation of the world system in the 2000. International processes]. 2010. Vol. 8. N 1 (22). P. 4-13. (In Russ.)

Baranovskij V.G. Novaya vneshnyaya politika Rossii: vliyanie na mezhdunarodnuyu sistemu. Mirovaya ekonomika i mezhdunarodnye otnosheniya [New foreign policy of Russia: influence on the international system. World economy and international relations]. 2016. Vol. 60. N 7. P. 5-15. (In Russ.)

Bogaturov A.D., Kosolapov N.A., Hrustalev M.A. Ocherki teorii i metodologii politicheskogo analiza mezhdunarodnyx otnoshenij [Essays on the theory and methodology of the political analysis of international relations]. Moscow: NOFMO, 2002. 390 p. (In Russ.)

Vojtolovskij F.G. Ideologicheskaya refleksiya mirovoj politiki. Mezhdunarodnye processy [The ideological reflection of world politics. International processes]. 2007. Vol. 5. N 3 (15). P. 4456. (In Russ.)

Vojtolovskij F.G. Opredelenie strategicheskix celej - eto sfera ideologii... Mezhdunarodny`e processy [The definition of strategic goals is a sphere of ideology... International processes]. 2017. Vol. 15. N 1 (48). P. 157-168. (In Russ.) 
Gromyko Al.A. Postoyanstvo i izmenchivost' $v$ istorii mezhdunarodny`x otnoshenij. Sovremennaya Evropa [Consistency and variability in the history of international relations. The Modern Europe]. 2016. Vol. 1 (67). P. 5-8. (In Russ.)

Druzhilovskij S.B., Avatkov V.A. Vneshnepoliticheskie ideologemy Turcii (2002-2012 gg.). Obozrevatel [Foreign Policy Ideologemes of Turkey (2002-2012). Observer]. 2013. N 6 (281). P. $73-$ 88. (In Russ.)

Dynkin A.A. Krizis miroporyadka: poiski vyhoda [Crisis of the world order: the search for a way out. Scientific works of the Free Economic Society of Russia]. 2015. Vol. 196. P. 63-73. (In Russ.)

Inozemcev V., Karaganov S. O mirovom poryadke XXI veka. Rossiya v globalnoj politike [On the world order of the XXI century. Russia in global politics]. 2005. Vol. 3. N 1. P. 8-26. (In Russ.)

Kamenskaya G.V., Solov'ev E.G., Smirnov A.N. Politicheskie ideologii v sovremennom mire: krizis ili ocherednoj e'tap e'volyucii? Vlast [Political ideologies in the modern world: crisis or the next stage of evolution? Power] 2015. Vol. 23. N 12. P. 101-108. (In Russ.)

Karaganov S. Rossiya v mire peremen. Rossiya i musul 'manskij mir [Russia in a world of change. Russia and the Muslim world]. 2013. N 10 (256). P. 5-21. (In Russ.)

Karaganov S. Novaya ideologicheskaya bor`ba? [New ideological struggle?]. Izvestiya, 2016. April 21. URL: https://iz.ru/news/610812 (date of access: 11.05.2019). (In Russ.)

Kosolapov N.A. Krizis racional'noj vsemirnosti. Mezhdunarodnye processy [The crisis of rational universality. International processes]. 2006. V. 4. N 10. P. 55-67. (In Russ.)

Kremenyuk V.A. Upravlenie i upravlyaemost` v mirovoj politike. Mezhdunarodny`e processy [Management and manageability in world politics. International processes]. 2004. V. 2. N 3 (6). P. 29-39. (In Russ.)

Nikitina O. Lavrov: Mir stanovitsya postzapadny`m // Vzglyad [Lavrov: The world is becoming post-Western. View]. 2017. March 9. URL: https://vz.ru/news/2017/3/9/861152.html (date of access: 11.05.2019). (In Russ.)

Pahalyuk K.A. «Myagkaya sila» i politika pamyati v kontekste vneshnej politiki sovremennoj Rossii: tochki peresecheniya. Dnevnik ASHPI [«Soft power» and the politics of memory in the context of the foreign policy of modern Russia: intersection points. The Diary of the Altai School of Political Studies]. 2018. N 34. P. 134-141. (In Russ.)

Solov'ev E.G i Smirnov A.N. Mezhdunarodny`j imidzh sovremennoj Rossii: deficit privlekatel'nosti ili deficit idej? Polis. Politicheskie issledovaniya [The international image of modern Russia: lack of attractiveness or lack of ideas? Polis. Political Studies]. 2008. N 5. P. 19-33. (In Russ.)

Solov'ev E.G. Rukotvorny`j kontekst e`tnopolitiki // Mezhdunarodny`e process [Man-made ethno-political context. International processes]. 2008. Vol. 6. N 1 (16). P. 86-92. (In Russ.) 